\title{
Effects of the Electron-Deficient Third Components in n-Type Terpolymers on Morphology and Performance of All-Polymer Solar Cells
}

\author{
Bin Liu ${ }^{\mathrm{a}, \mathrm{b}, \mathrm{c}}$ \\ Huiliang Sun*a (D) \\ Chang Woo Koh ${ }^{d}$ \\ Mengyao Su ${ }^{\mathrm{a}}$ \\ Bao Tu \\ Yumin Tang ${ }^{\mathrm{a}}$ \\ Qiaogan Liao ${ }^{a}$ \\ Junwei Wang ${ }^{\mathrm{a}}$ \\ Wanli Yang ${ }^{\mathrm{a}}$ \\ Hong Meng b \\ Han Young Woo*d (i) \\ Xugang Guo*a (i) \\ ${ }^{a}$ Department of Materials Science and Engineering and The Shenzhen Key Laboratory \\ for Printed Organic Electronics, Southern University of Science and Technology \\ (SUSTech), No. 1088, Xueyuan Road, Shenzhen, Guangdong 518055, China

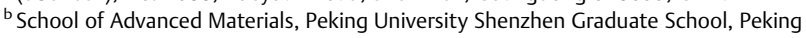 \\ University, Shenzhen 518055, China \\ Department of Physics, National University of Singapore, 2 Science Drive 3, Singapore \\ 117542, Singapore \\ ${ }^{\mathrm{d} D e p a r t m e n t ~ o f ~ C h e m i s t r y, ~ K o r e a ~ U n i v e r s i t y, ~ S e o u l ~ 136-713, ~ S o u t h ~ K o r e a ~}$ \\ sunh@@sustech.edu.cn, hywoo@korea.ac.kr, guoxg@sustech.edu.cn
}

Received: 29.04.2020

Accepted after revision: 26.05.2020

DOI: 10.1055/s-0040-1713857; Art ID: om-20-0012oa

License terms: $(9)(1) \ominus($

(c) 2020. The Author(s). This is an open access article published by Thieme under the terms of the Creative Commons Attribution-NonDerivative-NonCommercial-License, permitting copying and reproduction so long as the original work is given appropriate credit. Contents may not be used for commercial purposes, or adapted, remixed, transformed or built upon. (https://creativecommons.org/licenses/by-nc-nd/4.0/)

Abstract Compared with p-type terpolymers, less effort has been devoted to n-type analogs. Herein, we synthesized a series of n-type terpolymers via incorporating three electron-deficient third components including thienopyrroledione (TPD), phthalimide, and benzothiadiazole into an imide-functionalized parent n-type copolymer to tune optoelectronic properties without sacrificing the n-type characteristics. Due to effects of the third components with different electronaccepting ability and solubility, the resulting three polymers feature distinct energy levels and crystallinity. In addition, heteroatoms $(\mathrm{S}, \mathrm{O}$, and $\mathrm{N}$ ) attached on the third components trigger intramolecular noncovalent interactions, which can increase molecule planarity and have a significant effect on the packing structures of the polymer films. As a result, the best power conversion efficiency of $8.28 \%$ was achieved from all-polymer solar cells (all-PSCs) based on n-type terpolymer containing TPD. This is contributed by promoted electron mobility and face-on polymer packing, showing the pronounced advantages of the TPD used as a third component for thriving efficient n-type terpolymers. The generality is also successfully validated in a benchmark polymer donor/acceptor system by introducing TPD into the benchmark n-type polymer N2200. The results demonstrate the feasibility of introducing

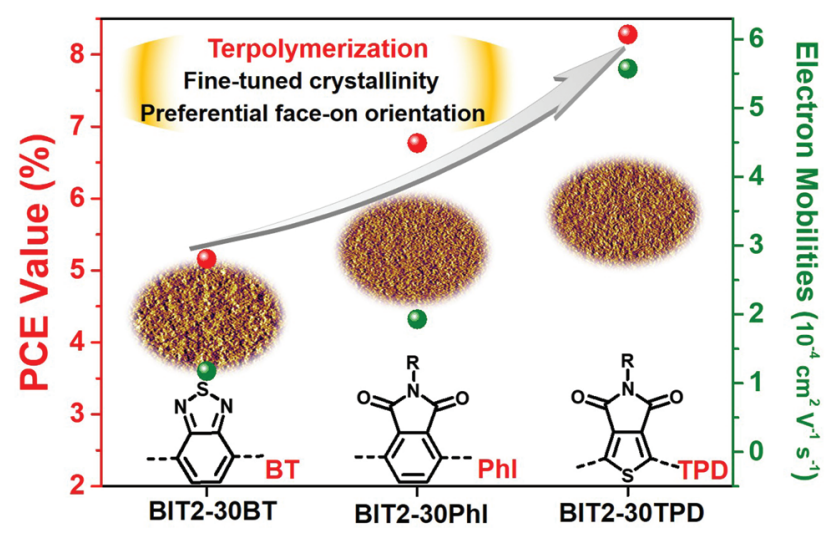

suitable electron-deficient building blocks as the third components for high-performance n-type terpolymers toward efficient all-PSCs.

Key words n-type terpolymers, electron-deficient building blocks, bulk morphology, imide-functionalized heteroarenes, all-polymer solar cells

\section{Introduction}

As a promising technology of renewable energy source, organic solar cells (OSCs) with a bulk-heterojunction (BHJ) structure have attracted increasing attention due to their prominent advantages of light weight, low-cost preparation, and huge potential in flexibility, semitransparency and largearea fabrication. ${ }^{1}$ In recent years, nonfullerene acceptors have been sprouting up to enhance the ability of capturing solar photon, significantly promoting the development of highperformance OSCs. ${ }^{2}$ Among them, all-polymer solar cells (allPSCs) incorporating a polymeric donor and acceptor as the photoactive layer have emerged as a promising alternative due to their intrinsic merits such as superior morphological stability and mechanical durability. ${ }^{3}$ However, their power conversion efficiencies (PCEs) still have lagged behind those of fused-ring electron-acceptor-based OSCs. ${ }^{4}$ One of the major challenges to further develop efficient all-PSCs is to achieve a 
favorable polymer/polymer blend morphology and packing structure, which can facilitate the charge carrier dissociation and determine PCEs of all-PSCs. To this end, a variety of device methods have been exploited, including cosolvents, ${ }^{5}$ solution processing additives, ${ }^{6}$ and postdeposition treatment such as solvent vapor annealing. ${ }^{7}$ Although the photovoltaic performances of all-PSCs have been successfully progressed to varying degrees, these extra complexities of device fabrication increase time and energy consumption, making the large-area and low-cost industrialization of OSCs a singular challenge. ${ }^{8}$

Recently, the approach of random terpolymerization, which involves the incorporation of a third component into the parent copolymer, has been observed to lead to generation of fine-tuned optoelectronic properties and crystallinity of the resulting terpolymers. ${ }^{9}$ In comparison to a large variety of p-type terpolymers with excellent device performance, the development of n-type terpolymers greatly lags behind due to the limited electron-deficient building blocks. Integrating the advantages of available electron-deficient building blocks (introducing the electron-deficient third component into n-type copolymers) to construct random terpolymers with optimized molecular geometry and improved electronic property is a simple and effective approach. For instance, Jenekhe et al introduced larger size perylene diimide (PDI) into a naphthalene diimide (NDI)-selenophene copolymer to reduce its strong crystallinity/aggregation and improve compatibility with the polymer donor. ${ }^{3 \mathrm{c}}$ The resulting n-type terpolymer yields a significant enhanced performance ( $\mathrm{PCE}=6.3 \%$ vs. $1.4 \%$ ). Recently, an electron-deficient dye unit was incorporated into the benchmark n-type copolymer N2200 via random terpolymerization by Chen and coworkers, resulting in not only a reduced crystallinity but also an improved light absorption coefficient and an upshifted LUMO energy level. ${ }^{9 a}$ Consequently, the n-type terpolymer demonstrated a higher PCE of $8.13 \%$ compared to that of N2200 (5.15\%). In addition, two similar electron-deficient building blocks containing different side chains were also employed to synthesize terpolymers. For example, an oligoethylene oxide-modified NDI unit was used by Huang et al. as the third component in the terpolymerization reaction for morphology optimization. ${ }^{4 \mathrm{~d}}$ The resulting NDI terpolymers have achieved an improved PCE with a remarkable fill factor (FF) of up to $75 \%$ and excellent stability with $97 \%$ of its initial PCE being retained after $300 \mathrm{~h}$ of aging at $65^{\circ} \mathrm{C}$ compared to the parent polymers. These results clearly suggest that random terpolymerization with the incorporation of the electron-deficient third components is an effective strategy for promoting PCEs in all-PSCs and this strategy enables allPSCs with improved device stability.

Among various electron-deficient building blocks, fused bithiophene imide (BTI) oligomers have proved to be highly effective ones, e.g., the fused BTI dimer BTI2. The pioneering work of Osaka and coworkers has manifested that BTI2 is a versatile electron-deficient building block for polymer semiconductors. ${ }^{10}$ Our group implements the application of BTI2-based n-type polymers in all-PSCs. ${ }^{11}$ These polymers feature much more tunable LUMO levels due to their delocalized topology along polymer backbones compared to classical NDI and PDI-based polymers, which is desirable for reducing energy loss and improving $V_{\text {oc }}$ in all-PSCs by minimizing the energy offsets between the polymer donors and acceptors. For example, a copolymer, BTI2-FT (a.k.a. fBTI2-FT), of BTI2 and 3,4-difluorothiophene shows a PCE of $6.8 \%$ with a large $V_{\text {oc }}$ of $1.01 \mathrm{~V}^{12}$

Inspired by the success of both terpolymerizationstrategy-based two electron-deficient building blocks and BTI2 for developing all-PSCs, here, a series of BTI2-based ntype terpolymers (BTI2-30BT, BTI2-30PhI, and BTI2-30TPD) was designed and synthesized by random polymerization. Therein, three electron-deficient building blocks, benzothiadiazole (BT), phthalimide (PhI) and thienopyrroledione (TPD), with distinct electron-accepting ability and solubility used as the third components were incorporated into the parent polymer BTI2-FT, respectively (Figure 1a). These terpolymers are designed to investigate the effects of the electron-deficient third component on morphological characteristics and photovoltaic properties. They possess sequentially decreasing LUMO energy levels and increased crystallinity from BTI2-30PhI to BTI2-30TPD to BTI2-30BT, leading to distinct energy offset and miscibility when blended with the polymer donor PTB7-Th. Moreover, heteroatoms $(\mathrm{S}, \mathrm{O}$, and $\mathrm{N})$ attached to the polymer backbone trigger intramolecular noncovalent interactions, resulting in an increased molecular planarity and having a significant effect on the packing structure. The best PCE was attained from BTI2-30TPD/PTB7-Th combination benefited from promoted electron mobility and face-on polymer packing, which suggested the marked superiority of the electron-
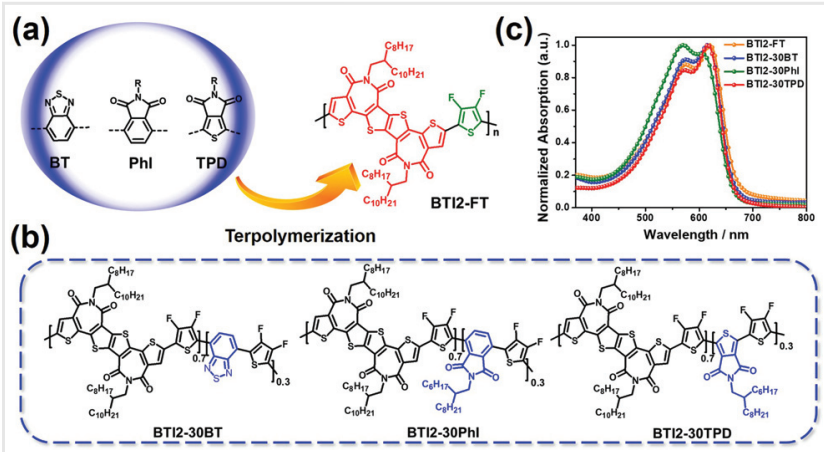

Fig. 1 (a) Terpolymerization via incorporating the electron-deficient third components BT, Phl, and TPD units into the BTI-based polymer BTI2-FT. (b) Chemical structures of BTI2-30X terpolymer acceptors used in this work. (c) UV-vis absorption spectra of neat BTI2-FT and terpolymer films. 
deficient third component for developing efficient terpolymer acceptors. This strategy is further validated in PTB7-Th: N2200 blends, where TPD was introduced into the benchmark n-type polymer N2200. The improved PCEs were achieved by TPD-based n-type terpolymers. These results demonstrate the superiority of electron-deficient third components for high-performance n-type terpolymers and pave the way toward high-efficiency all-PSCs.

\section{Results and Discussion}

\section{Polymer Synthesis and Properties}

Our design for terpolymers is based on previously reported procedures. ${ }^{12}$ The copolymers were synthesized by Stille coupling polymerization of the following monomers: f-BTI2-Br, BT-Br, PhI-Br, TPD-Br, and FT (Figure 1b and Scheme S1). The new n-type semiconducting, random BTIbased terpolymers are denoted as BTI2-30X, where X is the co-monomer unit. Based on our previous study, $30 \%$ was chosen as the optimal proportion in the BTI terpolymer backbone, ${ }^{12}$ i.e., BTI2-30BT (30\% BT moiety), BTI2-30TPD (30\% TPD moiety), and BTI2-30PhI (30\% PhI moiety), respectively (Figure $1 \mathrm{~b}$ ). Meanwhile, the parent copolymer BTI2-FT was synthesized as the reference polymer. ${ }^{3 \mathrm{n}}$ The BTI2-30X samples showed excellent solubility in frequently used organic solvents (e.g., chlorobenzene, dichlorobenzene, and chloroform). The chemical structures of all the terpolymers were confirmed by the ${ }^{1} \mathrm{H}$ NMR data (Figures S10,S11,S12,S13), and their molecular weight $\left(M_{n}\right)$ and dispersity $(Đ)$ were obtained via gel permeation chromatography at $120{ }^{\circ} \mathrm{C}$ with 1,2,4-trichlorobenzene as the eluent (Table 1). Thermogravimetric analysis results of all the polymers presented an onset decomposition temperature $\left(T_{\mathrm{d}}\right)$ over $380{ }^{\circ} \mathrm{C}$, suggesting their excellent thermal stability in the fabrication and optimization of all-PSCs (Figure S1).

In addition, the normalized UV-vis absorption spectra of the polymer films are shown in Figure 1c and the optical properties are summarized in Table 1 . The third compo-

Table 1 Basic properties of polymer acceptors BTI2-FT, BTI2-30BT, BTI2-30Phl, and BTI2-30TPD

\begin{tabular}{lllllll}
\hline $\begin{array}{l}\text { Polymer } \\
\text { acceptor }\end{array}$ & $\begin{array}{l}M_{\mathrm{n}} \\
(\mathrm{kDa})^{\mathrm{a}}\end{array}$ & $\bigoplus$ & $\begin{array}{l}\lambda_{\text {onset in }} \\
\text { film }(\mathrm{nm})\end{array}$ & $\begin{array}{l}E_{\mathrm{g}}^{\mathrm{opt}} \\
(\mathrm{eV})^{\mathrm{b}}\end{array}$ & $\begin{array}{l}\text { HOMO } \\
(\mathrm{eV})^{\mathrm{c}}\end{array}$ & $\begin{array}{l}\text { LUMO } \\
(\mathrm{eV})^{\mathrm{c}}\end{array}$ \\
\hline BTI2-FT & 19.6 & 2.4 & 675 & 1.84 & -5.27 & -3.43 \\
BTI2-30BT & 16.7 & 2.6 & 665 & 1.86 & -5.35 & -3.49 \\
BTI2-30PhI & 12.7 & 2.3 & 658 & 1.88 & -5.27 & -3.39 \\
BTI2-30TPD & 17.6 & 2.9 & 663 & 1.87 & -5.28 & -3.41 \\
\hline
\end{tabular}

a Determined by gel permeation chromatography.

${ }^{\mathrm{b}} E_{\mathrm{g}}^{\mathrm{opt}}=1240 / \lambda_{\text {onset }}$.

${ }^{\mathrm{C}} \mathrm{HOMO}=\mathrm{E}_{\mathrm{g}}{ }^{\mathrm{Opt}}-$ LUMO. nents possess comparable electron-withdrawing ability with BTI2 in parent polymers, along with intramolecular noncovalent interactions triggered by heteroatoms attached on our terpolymer and the small size of the third components, ${ }^{9 a, 7,13}$ resulting in almost the same intramolecular charge transfer absorption peak at about 400-$650 \mathrm{~nm} .{ }^{3 \mathrm{n}}$ Despite this, the absorption spectrum for BTI230PhI has a slight blue shift compared to those of BTI2-30BT and BTI2-30TPD terpolymers, which is on account of the relatively twisted structure for BTI2-30PhI due to steric hindrance from $\mathrm{PhI}$ and adjacent fluorinated thiophene (Figure S3). The optical bandgap $\left(E_{\mathrm{g}}{ }^{\mathrm{opt}}\right.$ ) values of these copolymers can be calculated from the absorption onset of films, and are comparably in the range of $1.84-1.88 \mathrm{eV}$. The HOMO and LUMO levels were obtained by cyclic voltammetry. As displayed in Figures $2 b$ and S2, due to the distinct electron-withdrawing ability of BT, TPD, and PhI units, the sequentially decreasing LUMO energy levels from BTI230PhI to BTI2-30TPD to BTI2-30BT can be observed. Their corresponding HOMO/LUMO energy levels were calculated to be $-5.27 /-3.39,-5.28 /-3.41$, and $-5.35 /-3.49 \mathrm{eV}$, for BTI2-30PhI, BTI2-30TPD, and BTI2-30BT, respectively (Table 1), which showed trends consistent with the density functional theory (DFT) calculation ${ }^{14}$ (Figure S3). In addition, the backbone conformation was elucidated by DFT calculation. Benefiting from the reduced steric hindrance between BTI2 and the adjacent thiophene ring along with intermolecular noncovalent interaction induced by the heteroatom attached on polymer backbone, BTI2-30BT and BTI2-30TPD show almost planar geometries. However, there is a $22.8^{\circ}$ dihedral angle between $\mathrm{PhI}$ and the adjacent 3,4difluorothiophene, resulting in a relatively twisted molecular backbone and thus a slightly blue-shifted absorption spectrum of BTI2-30PhI.
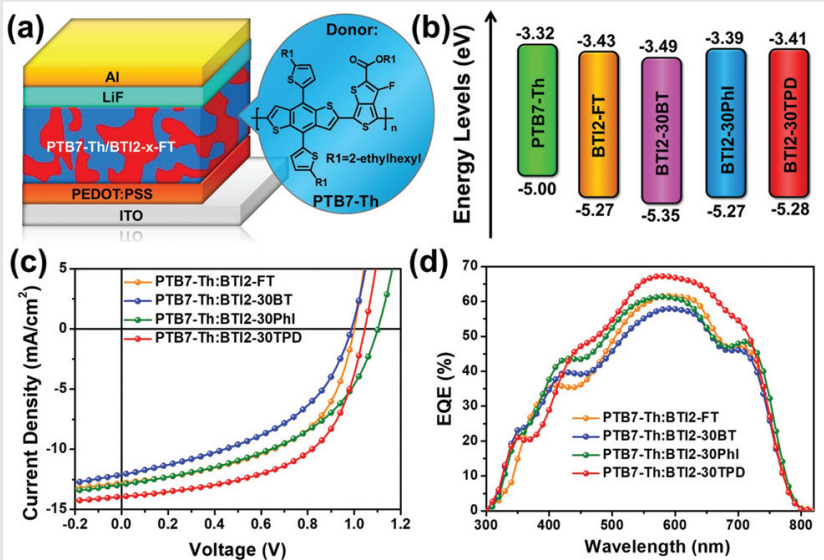

Fig. 2 (a) Device architecture and chemical structure of the donor polymer PTB7-Th. (b) Energy level diagram of PTB7-Th, BTI2-FT, and BTI2-30X terpolymer acceptors. (c) Current density-voltage (J-V) curves under AM 1.5G (100 $\left.\mathrm{mW} \mathrm{cm}^{-2}\right)$. (d) EQE spectra of the optimized devices. 


\section{B. Liu et al.}

\section{Photovoltaic Performances}

To evaluate the photovoltaic properties of the BTI2-30BT, BTI2-30PhI, and BTI2-30TPD terpolymers, all-PSCs were fabricated using PTB7-Th as the polymer donor with a device structure of ITO/PEDOT:PSS/Active Layers/LiF/Al (Figure 2a). The all-PSCs were prepared after carefully optimizing in terms of D/A ratios, thickness, annealing temperature, and various electron transporting layers (Tables S1-S5). The optimal blend films ( $\mathrm{D}: \mathrm{A}=1: 2 \mathrm{wt} . \%$ ) dissolved in chlorobenzene solvent (total concentration: $16 \mathrm{mg} \mathrm{mL}^{-1}$ ) were deposited using the spin-coating method without any solvent additives, and the fabricated devices were measured under $100 \mathrm{~mW} / \mathrm{cm}^{2}$ AM $1.5 \mathrm{G}$ solar illumination. The typical current density-voltage $(J-V)$ curves of the all-PSCs are shown in Figure $2 c$ and the corresponding photovoltaic parameters are summarized in Table 2. As observed from the $J-V$ curves, the reference PTB7-Th:BTI2-FT solar cell achieved a maximum PCE of $6.84 \%$ with a $J_{\mathrm{sc}}$ of $12.80 \mathrm{~mA} / \mathrm{cm}^{2}$, a $V_{\text {oc }}$ of $1.01 \mathrm{~V}$, and an FF of $52.97 \%$, which are consistent with the previous reports. ${ }^{12}$ With the incorporation of the third components in the backbones of polymer acceptors, the $V_{\text {oc }}$ of the all-PSCs increased in the order: BTI2-30BT $(0.99 \mathrm{~V})<$ BTI2-30TPD $(1.05 \mathrm{~V})<$ BTI2-30PhI $(1.08 \mathrm{~V})$, due to the gradually decreasing energy offset $(\Delta E)$ between the polymer donor PTB7-Th and the terpolymer acceptors (Figure $2 \mathrm{~b}) .{ }^{15}$ Notably, profited from the high-lying LUMO levels of the BTIbased n-type polymer, the $V_{\text {oc }}$ values of all-PSC devices are basically $\geq 1.0 \mathrm{~V}$. Interestingly, the PCEs of the terpolymer acceptors displayed a linear component correlation. To be more specific, the corresponding efficiencies increased from $5 \%$ to $8 \%$ in the sequence BTI2-30BT $(5.48 \%)<\mathrm{BTI} 2-30 \mathrm{PhI}$ $(6.80 \%)<$ BTI2-30TPD (8.28\%), which is in accordance with the observed increase of $J_{\text {sc }}$ and FF. For instance, the gradually increasing $J_{\mathrm{sc}}$ exhibited the values of $12.11,12.91$, and $13.56 \mathrm{~mA} \mathrm{~cm}^{-2}$ for the terpolymers of BTI2-30BT, BTI230PhI, and BTI2-30TPD, respectively. A similar increasing trend for the FF values can also be observed. Obviously, the PCE changes of these terpolymers can be ascribed to the increase of $J_{\mathrm{sc}}$ and FF values, which were closely associated with the miscibility and morphology of polymer films (see Figure 4).

To further confirm the accuracy of the $J-V$ results, the external quantum efficiency (EQE) spectra of the BTI2-FT- and BTI2-30X-based PSC devices are plotted and shown in Figure 2d. Similarly, the EQE curves of the all-PSCs displayed both high and broad photoresponses in the spectral range from 300 to $800 \mathrm{~nm}$. The shapes of the curves are consistent with the corresponding absorption spectra, and the integrated $J_{\text {sc }}$ values obtained from the EQE spectra are in good agreement ( $<5 \%$ error) with those from the $J-V$ measurements of the optimized devices (Table 2). It is worth noting that the highest photoresponse efficiency (approaching 70\%) for the best-performing BTI2-30TPD-based device was achieved throughout the range of $550-650 \mathrm{~nm}$. This result further indicates that the optimal film morphology is effectively conducive to the light harvesting and photocurrent in the all-PSCs.

\section{Crystallinity, Packing Structures, and Morphology of Polymer Films}

To probe into the intramolecular stacking and nanostructured order of polymer films, 2D grazing-incidence wide-angle X-ray scattering (GIWAXS) measurement was conducted on the neat and blend thin films of the terpolymers. A $30-40 \mathrm{~nm}$ thin layer of PEDOT:PSS was spin-coated on the silicon substrate, and the neat or blend polymer films were prepared by spin-coating on the PEDOT: PSS layer. The GIWAXS images and in-plane (IP) and out-ofplane (OOP) line-cut patterns of BTI2-FT and BTI2-30X films are depicted in Figures $3 \mathrm{a}-\mathrm{d}$ and $\mathrm{i}-\mathrm{j}$, and their corresponding packing parameters are included in Table S6. All the neat films showed strong (100) lamellar scattering peaks at $\sim 0.24 \AA^{-1}$ along the IP $\left(q_{\mathrm{xy}}\right)$ and OPP $\left(q_{\mathrm{z}}\right)$ directions, which corresponded to a lamellar d-spacing of $\sim 26.0 \AA$ A. As BT, TPD, and $\mathrm{PhI}$ were incorporated into the BTI2-FT polymer backbone, the $\pi-\pi$ stacking distance in the IP direction for the BTI2-30BT and BTI2-30TPD films remained almost unchanged at $\sim 3.56 \AA$, while the BTI2-30PhI film showed a

\begin{tabular}{|c|c|c|c|c|c|}
\hline Active layer $^{a}$ & $V_{o c}(V)^{b}$ & $J_{s c}\left(m A c m^{-2}\right)^{b}$ & Cal. $\left.\int_{\mathrm{sc}}(\mathrm{mA} \mathrm{cm})^{-2}\right)^{\mathrm{c}}$ & $\mathrm{FF}(\%)^{\mathrm{b}}$ & PCE (\%) ${ }^{\mathrm{b}}$ \\
\hline PTB7-Th:BTI2-FT & $1.01(1.00 \pm 0.03)$ & $12.80(12.54 \pm 0.26)$ & 12.39 & $52.97(51.53 \pm 1.44)$ & $6.84(6.46 \pm 0.38)$ \\
\hline PTB7-Th:BTI2-30BT & $0.99(0.97 \pm 0.02)$ & $12.11(11.93 \pm 0.18)$ & 11.52 & $45.80(43.75 \pm 2.05)$ & $5.48(5.06 \pm 0.42)$ \\
\hline PTB7-Th:BTI2-30PhI & $1.08(1.06 \pm 0.02)$ & $12.91(12.79 \pm 0.12)$ & 12.43 & $48.75(47.29 \pm 1.46)$ & $6.80(6.41 \pm 0.39)$ \\
\hline PTB7-Th:BTI2-30TPD & $1.05(1.05 \pm 0.01)$ & $13.56(13.46 \pm 0.10)$ & 13.32 & $58.25(57.24 \pm 1.01)$ & $8.28(8.10 \pm 0.18)$ \\
\hline
\end{tabular}



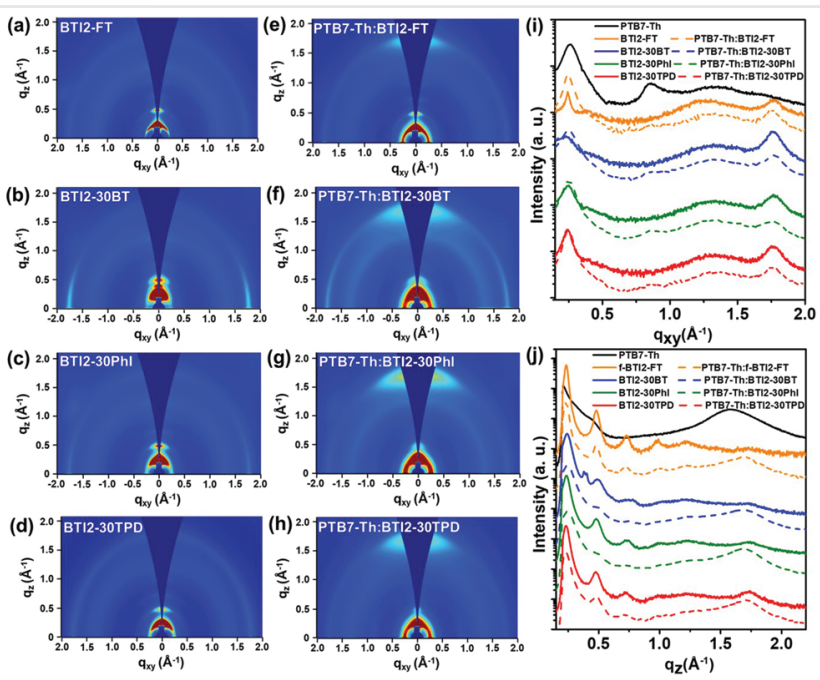

Fig. 3 (a-d) 2D GIWAXS images of the BTI2-FT and BTI2-30X neat films. (e-h) 2D GIWAXS images of the PTB7-Th:BTI2-FT and PTB7-Th:BTI2-

$30 X$ blend films; (e) in-plane and (f) out-of-plane line cuts of GIWAXS patterns of all neat and blend films.

slightly larger $\pi-\pi$ stacking distance of $3.58 \AA$ due to the twisted polymer backbone, which was in accordance with the UV-vis absorption of these terpolymers. Nevertheless, in general, the irregularity of the terpolymer backbone can still lead to a decrease in the crystallinity of the terpolymer. Besides, the neat BTI2-30BT shows an edge-on dominant orientation, while an increased face-on packing structure was observed for the terpolymers BTI2-PhI and BTI2-30TPD, which is likely related to the noncovalent S...O interaction. ${ }^{3 \mathrm{n} 16 \mathrm{~b}}$ These were in good agreement with electron mobilities of the neat films measured by space charge limited current method (SCLC; Table S10). ${ }^{16}$

In the PTB7-Th:BTI2-30X blend films, the decreased diffraction peak intensities as a function of introduced BT, TPD, and PhI in blend films suggest a relatively reduced crystallinity in the terpolymer-based blend films, which is closely related to the miscibility and compatibility with PTB7$\mathrm{Th}^{3 \mathrm{C}}$ In addition, an enhanced face-on orientation was observed in terpolymer-based blends, specifically, a gradually increase in face-on packing structures with more close $\pi-\pi$ stacking in OOP (010) orientations was observed from BTI30BT to BTI-30PhI to BTI-30TPD. This observed trend was similar to that of neat films due to effects of the intramolecular noncovalent interactions and improved miscibility (Table S7). Such a situation has also been observed in other type of PSCs based on fullerene and fused-ring electron acceptors. ${ }^{16 \mathrm{~b} 17}$ In our case, S...O and S...F noncovalent interactions in BTI230TPD were likely beneficial for promoting a planar $\pi$ backbone and interchain ordering with better solution processability, which can contribute to the charge carrier transport in the vertical direction, thereby improving the $J_{\mathrm{sc}}$ values for the BTI2-30TPD-based all-PSC devices.

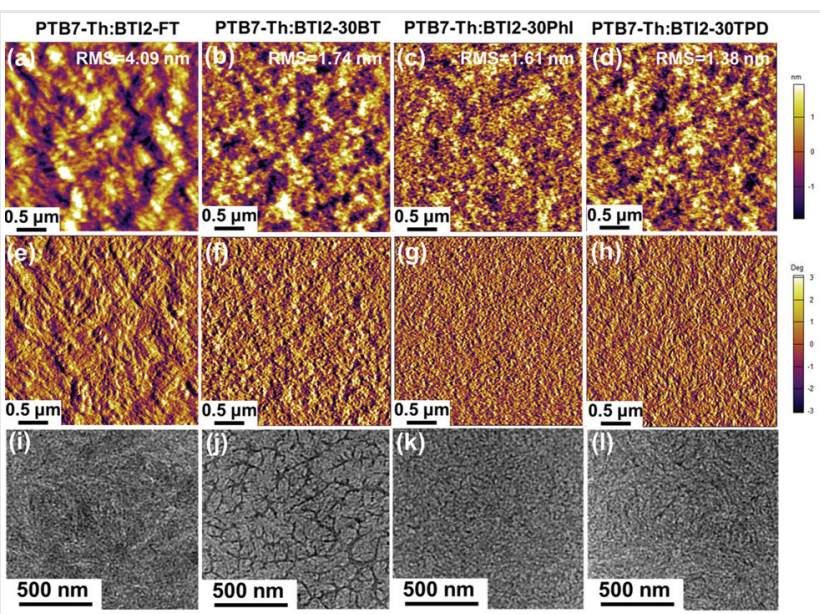

Fig. 4 AFM height images (a-d), phase images (e-h), and TEM images (i-I) of the PTB7-Th:BTI2-FT and PTB7-Th:BTI2-30X blend films.

The BHJ surface and bulk morphologies of the PTB7-Th: BTI2-30X blend films as well as the reference PTB7-Th:BTI2FT polymer blend were investigated by tapping-mode atomic force microscopy (AFM) and transmission electron microscopy (TEM). As displayed in Figure $4 a-h$, the as-cast PTB7-Th:BTI2-FT thin film exhibited a large-scale phase separation with a root mean square roughness $\left(R_{\mathrm{q}}\right)$ of $4.09 \mathrm{~nm}^{18}$ As the co-monomer units (BT, PhI, and TPD) were incorporated into the pristine BTI2-FT polymer, a dramatic change in film morphology was observed, and a much smoother surface was obtained. The $R_{\mathrm{q}}$ values decreased from $4.09 \mathrm{~nm}$ for the PTB7-Th:BTI2-FT blend to $1.74,1.61$, and $1.38 \mathrm{~nm}$ for the BTI2-30BT-, BTI2-30PhI-, and BTI2-30TPD-based blends, respectively, due to the irregular polymer backbone. ${ }^{3 n 19}$ Additionally, the TEM measurements (Figure $4 \mathrm{i}-\mathrm{l}$ ) demonstrated a gradual definite fibril structure stemmed from a bicontinuous interpenetrating network. In particular, the random BTI2-30TPD-based blend film was inclined to form a highly uniform and prominent nanofibrillar morphology, which agreed well with the $R_{\mathrm{q}}$ value and the significantly quenched photoluminescence efficiency (Figure S7). Thus, the favorable bulk morphology in the BTI2-30TPD-based blend led to a more effective exciton dissociation and charge transport, thereby boosting the $J_{\mathrm{sc}}$ and FF in the all-PSCs.

\section{Charge Dissociation, Recombination, and Transport Characteristic}

To evaluate the charge generation and charge collection processes, photocurrent density $\left(J_{\mathrm{ph}}=J_{\text {light }}-J_{\text {dark }}\right)$ versus effective voltage $\left(V_{\text {eff }}=V_{0}-V_{\text {app }}\right)$ curves were plotted for the investigated all-PSCs. Here, $V_{0}$ refers to the built-in voltage and $V_{\text {app }}$ is the applied voltage. As depicted 

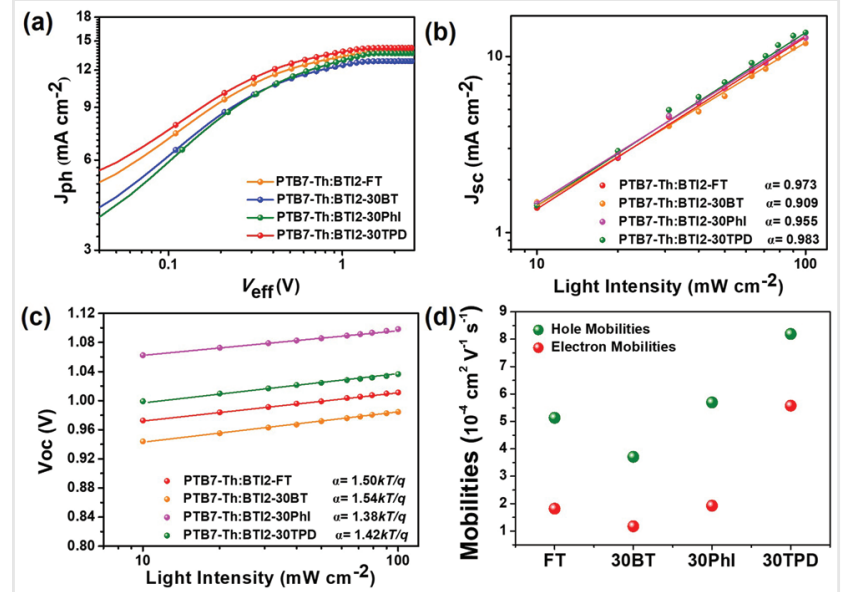

Fig. 5 (a) $P_{\text {diss }}$ versus $V_{\text {eff }}$ plots, (b) dependence of $/_{s c}$ on different light intensity, (c) light intensity dependence of $V_{\text {oc }}$, and (d) electron and hole SCLC mobilities of all-PSCs based on BTI2-FT or BTI2-30X polymer acceptors.

in Figure 5a, The $J_{\mathrm{ph}}$ values saturate at a high $V_{\text {eff }}$ of $\sim 1.0 \mathrm{~V}$, giving rise to saturation photocurrent densities $\left(J_{\text {sat }}\right)$ of about $12.84 \mathrm{~mA} \mathrm{~cm}^{-2}$ in BTI2-30BT, $13.65 \mathrm{~mA} \mathrm{~cm}^{-2}$ in BTI230PhI, and $14.21 \mathrm{~mA} \mathrm{~cm}^{-2}$ in BTI2-30TPD (Table S8). At the near-saturation point, the effective voltage $\left(V_{\text {eff }}\right)$ is large enough to dissociate almost all the photogenerated free excitons, suggesting the excellent carrier extraction capability of all the polymer/polymer blends. Next, the charge collection probability $\left(P_{\text {diss }}\right)$ was calculated by $J_{\mathrm{ph}} / J_{\mathrm{sat}}$ to investigate the charge carrier collection ability of the PTB7Th:BTI2-30X blends under short-circuit conditions. The $P_{\text {diss }}$ values were determined to be $92.73 \%, 93.74 \%$, and $95.24 \%$ for the BTI2-30BT-, BTI2-30PhI-, and BTI2-30TPD-based devices, respectively, which are in agreement with the corresponding PL quenching efficiencies. The higher $P_{\text {diss }}$ value indicated that a more effective exciton dissociation and collection occurred in the PTB7-Th:BTI2-30TPD device in comparison with the other all-PSCs. This result implies that there can form more favorable bulk morphologies in the BTI2-30X-based blends with the incorporation of the BT, $\mathrm{PhI}$, and TPD electron-deficient units in sequence, ultimately resulting in greatly enhanced $J_{\mathrm{sc}}$ in BTI2-30TPD-based devices. $^{3 \mathrm{~g}}$

In order to explore charge carrier recombination kinetics, the $J_{\mathrm{sc}}$ value as a function of light intensity $\left(P_{\text {light }}\right)$ was measured using the equation: $J_{\mathrm{sc}} \propto P_{\text {light }}{ }^{\alpha}$, thereinto $\alpha$ $\sim 1$ means negligible bimolecular recombination. ${ }^{20}$ The determined $\alpha$ values were $0.973,0.955$, and 0.983 for PTB7-Th:BTI2-FT, PTB7-Th:BTI2-30PhI, and PTB7-Th:BTI2$30 \mathrm{TPD}$, respectively (Figure $5 \mathrm{~b}$ ). These results suggest the relatively suppressed charge recombination in their corresponding devices. In contrast, the $\alpha$ value for the BTI2-30BT-based device was merely 0.909 , which corre- sponded to the poor FF performance. Additionally, the $P_{\text {light }}$ dependence of $V_{\mathrm{oc}}$ was also applied to study the geminate recombination loss. As seen in Figure $5 \mathrm{c}$, all the BTI2-30Xbased devices exhibited a small dependence of $V_{\text {oc }}$ on $P_{\text {light }}$ with a slope of $1.3-1.5 \mathrm{kT} / \mathrm{q}$, indicating a reduced geminate recombination loss. These results further suggest that the enhanced $J_{\mathrm{sc}}$ values of the PTB7-Th:BTI2-30TPD devices were indeed due to the favorable microstructural compatibility via introducing TPD units to the pristine BTI2-FT polymer.

Furthermore, the bulk vertical hole and electron mobilities in the neat and all-polymer blend films were measured to explore the charge transport characteristics via the SCLC method. ${ }^{21}$ The $J^{1 / 2}-\left(V_{\mathrm{appl}}-V_{\mathrm{bi}}\right)$ curves and SCLC data are plotted in Figures $5 d$ and S4, S5, S6, and the charge carrier mobilities are included in Tables S9 and S10. For the neat films, the calculated electron mobility $\left(\mu_{\mathrm{e}}\right)$ of the BTI2FT neat film was $2.40 \times 10^{-4} \mathrm{~cm}^{2} \mathrm{~V}^{-1} \mathrm{~s}^{-1}$. By contrast, the $\mu_{\mathrm{e}}$ values for the PhI and TPD unit-incorporated terpolymers were significantly improved. In particular, the electron mobility increased by about threefold in the BTI2-30TPD films $\left(\mu_{\mathrm{e}}=7.11 \times 10^{-4} \mathrm{~cm}^{2} \mathrm{~V}^{-1} \mathrm{~s}^{-1}\right.$, which was the highest mobility value among the four polymer acceptors). Similarly for the blend films, hole mobilities $\left(\mu_{\mathrm{h}}\right)$ of $3.71 \times 10^{-4}$, $5.69 \times 10^{-4}$, and $8.19 \times 10^{-4} \mathrm{~cm}^{2} \mathrm{~V}^{-1} \mathrm{~s}^{-1}$ for BTI2-30BT, BTI2-30PhI, and BTI2-30TPD were obtained, and the corresponding $\mu_{\mathrm{e}}$ values were $1.18 \times 10^{-4}, 1.93 \times 10^{-4}$, and $5.57 \times 10^{-4} \mathrm{~cm}^{2} \mathrm{~V}^{-1} \mathrm{~s}^{-1}$, respectively. Clearly, the substantial increase of charge carrier mobilities indicated that a more beneficial bulk morphology has been tuned in the BTI2-30TPD blend, leading to more efficient charge transporting than the reference BTI2-FT blends. Moreover, a more balanced charge mobility $\left(\mu_{\mathrm{h}} / \mu_{\mathrm{e}}=1.47\right)$ was achieved in the PTB7-Th:BTI2-30TPD blend, which explains the improvement of photocurrent in the all-PSCs. ${ }^{22}$ The stepwise increasing and balanced charge mobilities for the neat and blend copolymer films provided further evidence of a preferential face-on orientation packing and reduced crystallinity in the BTI2-30TPD terpolymers, which has been discussed in the GIWAXS part. ${ }^{23}$

To demonstrate the generality of our method, a new terpolymer acceptor N2200-30TPD (30\% TPD moiety) was synthesized via incorporating TPD as the third component into the classical N2200 polymer (Figure S8). We fabricated the all-PSCs based on PBT7-Th:N2200 and PBT7-Th:N220030TPD blends, respectively. The $J-V$ plots of the all-PSC devices based on two blends are shown in Figure S9. The allPSC devices with N2200-30TPD as the electron acceptor showed improved $J_{\mathrm{sc}}$ and $\mathrm{FF}$, resulting in an improved PCE of $4.03 \%$, which is higher than that (PCE $=2.89 \%$ ) of PBT7-Th: N2200 blend and the previous result (3.7\%; Table S11). ${ }^{7}$ This result indicates that our method is a general approach to optimize the active layer morphology and improve the device performance of all-PSCs. 


\section{Conclusions}

In summary, a new series of BTI2-based n-type terpolymers BTI2-30BT, BTI2-30PhI, and BTI2-30TPD were successfully synthesized and characterized via random polymerization. Due to the incorporation of the BT, PhI and TPD units with different electron-accepting ability and solubility, distinct energy levels and crystallinity can be observed for the corresponding terpolymer structures. Furthermore, S, O, and $\mathrm{N}$ heteroatoms attached on the third components induced intramolecular noncovalent interactions, which can make a significant difference in the molecular planarity and packing structures. The elevated photovoltaic performance of the BTI230TPD-based devices was derived from the synergistic effects of the favorable face-on orientation and suitable crystallites, which demonstrated the significant advantages of TPD as a third component. TPD was also incorporated into the PTB7-Th: N2200 system, leading to an improved PCE. Consequently, these findings suggest that the introduction of an appropriate third electron-deficient building block into the polymer backbones can be an effective method for tuning the optoelectronic properties and crystallinity of the resulting terpolymer without sacrificing the electron mobilities, which can broaden the pool of polymer acceptors for highly efficient all-PSCs.

\section{Experimental Section}

\section{Fabrication and Characterization of All-PSCs}

The ITO glasses ( $12 \Omega \mathrm{sq}^{-1}$ ) were cleaned according to a common procedure by sequential ultrasonic treatment in detergent, deionized water, acetone, and isopropanol for 15 minutes at each step. PEDOT:PSS (Clevios P VP A1 4083) was spin-coated onto UV-ozone (UVO) treated ITO substrates at $3000 \mathrm{rpm}$ for $30 \mathrm{~s}$ and annealed at $150{ }^{\circ} \mathrm{C}$ for $15 \mathrm{~min}$ in air to form a $40-\mathrm{nm}$ film. Then the PEDOT:PSScoated ITO substrates were transferred into a $\mathrm{N}_{2}$-filled glove box for subsequent steps. The PTB7-Th:BTI2-FT and PTB7Th:BTI2-30X solutions with various weight ratios were prepared with a total concentration of $16 \mathrm{mg} \mathrm{mL}^{-1}$ in chlorobenzene without any additives. The solutions were stirred overnight to achieve complete dissolution. The active layer with an optimal thickness of $120-150 \mathrm{~nm}$ was spincoated onto the PEDOT:PSS layer. Then, $0.8 \mathrm{~nm} \mathrm{LiF}$ and $110 \mathrm{~nm}$ Al were sequentially deposited atop the active layer via thermal evaporation under vacuum $\left(\mathrm{ca} .1 \times 10^{-5} \mathrm{~Pa}\right)$ to obtain an effective area of $0.045 \mathrm{~cm}^{2}$ for the solar cells. Before evaluating the performance of the solar cells, all devices were thermally annealed at $80{ }^{\circ} \mathrm{C}$ for $5 \mathrm{~min}$.

For device characterization, the current-voltage $(J-V)$ characteristics of the devices were obtained under simulated AM 1.5G irradiation ( $\left.100 \mathrm{~mW} / \mathrm{cm}^{2}\right)$ using a Xe lamp-based SS-
F5-3A solar simulator (Enli Technology, Inc.). A Xe lamp equipped with an AM 1.5G filter was used as the light source. The light intensity was controlled with an NREL-calibrated Si solar cell with a KG-5 filter. The EQE was collected using a QER3011 measurement system (Enli Technology, Inc.).

\section{Funding Information}

H.S. thanks NSFC (21801124) for the financial support. X.G. is grateful to the Shenzhen Basic Research Fund (JCYJ2017 0817105905899) and the Shenzhen Peacock Plan Project (KQTD20140630110339343). H.M. is grateful to the Shenzhen Science and Technology research grant (JCYJ2018030 2153406868) and Shenzhen Hong Kong Innovation Circle Joint R and D project (SGLH20161212101631809). B.L. thanks China Scholarship Council Fund (No.201906010074).H.Y.W. is grateful for the financial support from the National Research Foundation (NRF) of Korea (2019R1A6A1A11044070).

\section{Acknowledgment}

The authors thank Dr. Yinhua Yang at the Materials Characterization and Preparation Center, Southern University of Science and Technology (SUSTech), for NMR measurement. Our work was also supported by the Center for Computational Science and Engineering of SUSTech.

\section{Supporting Information}

Supporting information for this article is available online at http://doi.org/10.1055/s-0040-1713857.

\section{References}

(1) Heeger, A. J. Adv. Mater. 2014, 26, 10.

(2) (a) Yuan, J.; Zhang, Y.; Zhou, L.; Zhang, G.; Yip, H.-L.; Lau, T.-K.; Lu, X.; Zhu, C.; Peng, H.; Johnson, P. A. Joule 2019, 3, 1140. (b) Cai, F.; Zhu, C.; Yuan, J.; Li, Z.; Meng, L.; Liu, W.; Peng, H.; Jiang, L.; Li, Y.; Zou, Y. Chem. Commun. 2020, 56, 4340. (c) Li, S.; Li, C.-Z.; Shi, M.; Chen, H. ACS Energy Lett. 2020, 5, 1554. (d) Zhang, J.; Liu, W.; Xu, S.; Zhu, X. Org. Mater. 2019, 1, 30. (e) Liao, Q.; Kang, Q.; Yang, Y.; An, C.; Xu, B.; Hou, J. Adv. Mater. 2019, 32, 1906557. (f) Xu, X.; Feng, K.; Bi, Z.; Ma, W.; Zhang, G.; Peng, Q. Adv. Mater. 2019, 31, 1901872. (g) Ma, R.; Liu, T.; Luo, Z.; Guo, Q.; Xiao, Y.; Chen, Y.; Li, X.; Luo, S.; Lu, X.; Zhang, M. Sci. China Chem. 2020, 63, 325. (h) An, Q.; Ma, X.; Gao, J.; Zhang, F. Sci. Bull. 2019, 64, 504. (i) Cui, Y.; Yao, H.; Zhang, J.; Zhang, T.; Wang, Y.; Hong, L.; Xian, K.; Xu, B.; Zhang, S.; Peng, J. Nat. Commun. 2019, 10, 1. (j) Guo, Q.; Ma, R.; Hu, J.; Wang, Z.; Sun, H.; Dong, X.; Luo, Z.; Liu, T.; Guo, X.; Guo, X. Adv. Funct. Mater. 2020, 30, 2000383. (k) Yan, C.; Liu, T.; Chen, Y.; Ma, R.; Tang, H.; Li, G.; Li, T.; Xiao, Y.; Yang, T.; Lu, X. Solar RRL 2020, 4, 1900377. (l) Liu, T.; Gao, W.; Zhang, G.; Zhang, L.; Xin, J.; Ma, W.; Yang, C.; Yan, H.; Zhan, C.; Yao, J. Solar RRL 2019, 3, 
1800376. (m) Liu, L.; Kan, Y.; Gao, K.; Wang, J.; Zhao, M.; Chen, H.; Zhao, C.; Jiu, T.; Jen, A. K. Y.; Li, Y. Adv. Mater. 2020, 32, 1907604. (n) Dong, Y.; Zou, Y.; Yuan, J.; Yang, H.; Wu, Y.; Cui, C.; Li, Y. Adv. Mater. 2019, 31, 1904601. (o) Li, K.; Wu, Y.; Li, X.; Fu, H.; Zhan, C. Sci. China Chem. 2020, 63, 490. (p) Sun, H.; Liu, T.; Yu, J.; Lau, T.-K.; Zhang, G.; Zhang, Y.; Su, M.; Tang, Y.; Ma, R.; Liu, B. Energy Environ. Sci. 2019, 12, 3328.

(3) (a) Zhang, K.; Xia, R.; Fan, B.; Liu, X.; Wang, Z.; Dong, S.; Yip, H. L.; Ying, L.; Huang, F.; Cao, Y. Adv. Mater. 2018, 30, 1803166. (b) Wang, G.; Melkonyan, F. S.; Facchetti, A.; Marks, T. J. Angew. Chem. Int. Ed. 2019, 58, 4129. (c) Hwang, Y.-J.; Earmme, T.; Courtright, B. A.; Eberle, F. N.; Jenekhe, S. A. J. Am. Chem. Soc. 2015, 137, 4424. (d) Lee, C.; Lee, S.; Kim, G.-U.; Lee, W.; Kim, B. J. Chem. Rev. 2019, 119, 8028. (e) Choi, J.; Kim, W.; Kim, S.; Kim, T.-S.; Kim, B. J. Chem. Mater. 2019, 31, 9057. (f) Feng, W.; Lin, Z.; Lin, C.; Wang, W.; Ling, Q. ACS Appl. Mater. Interfaces 2019, 11, 43441. (g) Chen, S.; An, Y.; Dutta, G. K.; Kim, Y.; Zhang, Z. G.; Li, Y.; Yang, C. Adv. Funct. Mater. 2017, 27, 1603564. (h) Fan, Q.; Su, W.; Chen, S.; Kim, W.; Chen, X.; Lee, B.; Liu, T.; MéndezRomero, U. A.; Ma, R.; Yang, T. Joule 2020, 4, 658. (i) Yang, J.; Xiao, B.; Tang, A.; Li, J.; Wang, X.; Zhou, E. Adv. Mater. 2019, 31, 1804699. (j) Wang, W.; Wu, Q.; Sun, R.; Guo, J.; Wu, Y.; Shi, M.; Yang, W.; Li, H.; Min, J. Joule 2020, 4, 1070. (k) Fan, Q.; Ma, R.; Liu, T.; Su, W.; Peng, W.; Zhang, M.; Wang, Z.; Wen, X.; Cong, Z.; Luo, Z. Solar RRL 2020, 4, 2000142. (1) Wu, J.; Meng, Y.; Guo, X.; Zhu, L.; Liu, F.; Zhang, M. J. Mater. Chem. A 2019, 7, 16190. (m) Jia, T.; Zhang, J.; Zhong, W.; Liang, Y.; Zhang, K.; Dong, S.; Ying, L.; Liu, F.; Wang, X.; Huang, F. Nano Energy 2020, 72, 104718. (n) Zhou, K.; Wu, Y.; Liu, Y.; Zhou, X.; Zhang, L.; Ma, W. ACS Energy Lett. 2019, 4, 1057. (o) Sun, H.; Liu, B.; Koh, C. W.; Zhang, Y.; Chen, J.; Wang, Y.; Chen, P.; Tu, B.; Su, M.; Wang, H.; Guo, X. Adv. Funct. Mater. 2019, 29, 1903970. (p) Liu, X.; Li, X.; Li, Y.; Song, C.; Zhu, L.; Zhang, W.; Wang, H. Q.; Fang, J. Adv. Mater. 2016, 28, 7405.

(4) (a) Guo, Y.; Li, Y.; Awartani, O.; Han, H.; Zhao, J.; Ade, H.; Yan, H.; Zhao, D. Adv. Mater. 2017, 29, 1700309. (b) Kolhe, N. B.; Lee, H.; Kuzuhara, D.; Yoshimoto, N.; Koganezawa, T.; Jenekhe, S. A. Chem. Mater. 2018, 30, 6540. (c) Zhao, R.; Wang, N.; Yu, Y.; Liu, J. Chem. Mater. 2020, 32, 1308. (d) Liu, X.; Zhang, C.; Duan, C.; Li, M.; Hu, Z.; Wang, J.; Liu, F.; Li, N.; Brabec, C. J.; Janssen, R. A.; Bazan, G.C.; Huang, F.; Cao, Y. J. Am. Chem. Soc. 2018, 140, 8934. (e) Liu, S.; Chen, D.; Zhou, W.; Yu, Z.; Chen, L.; Liu, F.; Chen, Y. Macromolecules 2019, 52, 4359. (f) Zhao, C.; Wang, J.; Jiao, J.; Huang, L.; Tang, J. J. Mater. Chem. C 2020, 8, 28. (g) Meng, H.; Li, Y.; Pang, B.; Li, Y.; Xiang, Y.; Guo, L.; Li, X.; Zhan, C.; Huang, J. ACS Appl. Mater. Interfaces 2020, 12, 2733. (h) Duan, T.; Gao, J.; Babics, M.; Kan, Z.; Zhong, C.; Singh, R.; Yu, D.; Lee, J.; Xiao, Z.; Lu, S. Solar RRL 2020, 4, 1900472. (i) Lee, J.; Lee, S. M.; Chen, S.; Kumari, T.; Kang, S. H.; Cho, Y.; Yang, C. Adv. Mater. 2019, 31, 1804762. (j) Genene, Z.; Mammo, W.; Wang, E.; Andersson, M. R. Adv. Mater. 2019, 31, 1807275. (k) Jenekhe, S. A. Adv. Mater. 2016, 28, 124. (l) Wang, X.; Han, J.; Huang, D.; Wang, J.; Xie, Y.; Liu, Z.; Li, Y.; Yang, C.; Zhang, Y.; He, Z. ACS Appl. Mater. Interfaces 2020, 12, 20393. (m) Tang, A.; Xiao, B.; Wang, Y.; Gao, F.; Tajima, K.; Bin, H.; Zhang, Z. G.; Li, Y.; Wei, Z.; Zhou, E. Adv. Funct. Mater. 2018, 28, 1704507. (n) Xu, B.; Zheng, Z.; Zhao, K.; Hou, J. Adv. Mater. 2016, 28, 434. (o) Chen, K.; Ma, R.; Liu, T.; Luo, Z.; Xu, X.; Wang, Q.; Chen, Y.; Xiao, Y.; Lu, X.; Yan, H.J. Mater. Chem. A 2020, 8, 7083. (p) Liao, Q.; Sun, H.; Li, B.; Guo, X. Sci. Bull. 2019, 64, 1747. (q) Cai, Y.; Huo, L.; Sun, Y. Adv. Mater. 2017, 29, 1605437.

(5) (a) Yuan, J.; Xu, Y.; Shi, G.; Ling, X.; Ying, L.; Huang, F.; Lee, T. H.; Woo, H. Y.; Kim, J. Y.; Cao, Y. J. Mater. Chem. A 2018, 6, 10421. (b) Yuan, J.; Zhang, C.; Chen, H.; Zhu, C.; Cheung, S. H.; Qiu, B.; Cai, F.; Wei, Q.; Liu, W.; Yin, H.; Zhang, R.; Zhang, J.; Liu, Y.; Zhang, H.; Liu, W.; Peng, H.; Yang, J.; Meng, L.; Gao, F.; So, S.; Li, Y.; Zou, Y. Sci. China Chem. 2020. Doi: 10.1007/s11426-0209747-9.

(6) Earmme, T.; Hwang, Y. J.; Subramaniyan, S.; Jenekhe, S. A. Adv. Mater. 2014, 26, 6080.

(7) Li, Z.; Xu, X.; Zhang, W.; Meng, X.; Ma, W.; Yartsev, A.; Inganaäs, O.; Andersson, M. R.; Janssen, R. A.; Wang, E. J. Am. Chem. Soc. 2016, 138, 10935.

(8) (a) Jung, J. W.; Jo, J. W.; Chueh, C. C.; Liu, F.; Jo, W. H.; Russell, T. P.; Jen, A. K. Y. Adv. Mater. 2015, 27, 3310. (b) Luo, Z.; Sun, R.; Zhong, C.; Liu, T.; Zhang, G.; Zou, Y.; Jiao, X.; Min, J.; Yang, C. Sci. China Chem. 2020, 63, 361. (c) Ma, R.; Chen, Y.; Liu, T.; Xiao, Y.; Luo, Z.; Zhang, M.; Luo, S.; Lu, X.; Zhang, G.; Li, Y.J. Mater. Chem. C 2020, 8, 909. (d) Li, S.; Wen, X.; Zhou, J.; Zheng, N.; Liu, L.; Xie, Z. Org. Mater. 2020, 2, 071.

(9) (a) Chen, D.; Yao, J.; Chen, L.; Yin, J.; Lv, R.; Huang, B.; Liu, S.; Zhang, Z. G.; Yang, C.; Chen, Y. Angew. Chem. Int. Ed. 2018, 57, 4580. (b) Dang, D.; Yu, D.; Wang, E. Adv. Mater. 2019, 31, 1807019. (c) Duan, C.; Li, Z.; Pang, S.; Zhu, Y. L.; Lin, B.; Colberts, F. J.; Leenaers, P. J.; Wang, E.; Sun, Z. Y.; Ma, W. Solar RRL 2018, 2, 1800247. (d) Kim, S. W.; Kim, H.; Lee, J.-W. Lee, C.; Lim, B.; Lee, J.; Lee, Y.; Kim, B. J. Macromolecules 2019, $52,738$.

(10) Saito, M.; Osaka, I.; Suda, Y.; Yoshida, H.; Takimiya, K. Adv. Mater. 2016, 28, 6921.

(11) (a) Wang, Y.; Yan, Z.; Uddin, M. A.; Zhou, X.; Yang, K.; Tang, Y.; Liu, B.; Shi, Y.; Sun, H.; Deng, A. Solar RRL 2019, 3, 1900107. (b) Wang, Y.; Guo, H.; Ling, S.; Arrechea-Marcos, I.; Wang, Y.; López Navarrete, J. T.; Ortiz, R. P.; Guo, X. Angew. Chem. Int. Ed. 2017, 56, 9924.

(12) Wang, Y.; Yan, Z.; Guo, H.; Uddin, M. A.; Ling, S.; Zhou, X.; Su, H.; Dai, J.; Woo, H. Y.; Guo, X. Angew. Chem. Int. Ed. 2017, 56, 15304.

(13) Zhang, Y.; Tang, L.; Sun, H.; Ling, S.; Yang, K.; Uddin, M. A.; Guo, H.; Tang, Y.; Wang, Y.; Feng, K. Macromol. Rapid Commun. 2019, 40, 1900394.

(14) Li, Y.; Tatum, W. K.; Onorato, J. W.; Zhang, Y.; Luscombe, C. K. Macromolecules 2018, 51, 6352.

(15) Rogers, J. T.; Schmidt, K.; Toney, M. F.; Kramer, E. J.; Bazan, G. C. Adv. Mater. 2011, 23, 2284.

(16) (a) Guo, X.; Zhou, N.; Lou, S. J.; Smith, J.; Tice, D. B.; Hennek, J. W.; Ortiz, R. P.; Navarrete, J. T. L.; Li, S.; Strzalka, J. Nat. Photonics 2013, 7, 825. (b) Liu, Y.; Zhang, Z.; Feng, S.; Li, M.; Wu, L.; Hou, R.; Xu, X.; Chen, X.; Bo, Z. J. Am. Chem. Soc. 2017, 139, 3356. (c) Zhou, D.; Liu, Z.; Zhu, D.; Yuan, X.; Bao, X.; Yang, R. Org. Mater. 2019, 1, 71. (d) Cai, G.; Zhu, J.; Xiao, Y.; Li, M.; Liu, K.; Wang, J.; Wang, W.; Lu, X.; Tang, Z.; Lian, J. J. Mater. Chem. A 2019, 7, 21432.

(17) (a) Li, G.; Wang, S.; Li, D.; Liu, T.; Yan, C.; Li, J.; Yang, W.; Luo, Z.; Ma, R.; Wang, X. Solar RRL 2020, 4, 1900453. (b) Miao, J.; Meng, B.; Liu, J.; Wang, L. Org. Mater. 2019, 1, 88.

(18) Kang, H.; Lee, W.; Oh, J.; Kim, T.; Lee, C.; Kim, B. J. Acc. Chem. Res. 2016, 49, 2424.

(19) (a) Zhang, Y.-D.; Shi, L.-T.; Chen, Y.-W. Acta Polym. Sin. 2019, 50, 13. (b) Yang, C.; Yuan, L.; Zhou, R.; Wang, Z.; Zhang, J.; Zhang, Y.; Lu, K.; Wei, Z. Org. Mater. 2020, 2, 026.

(20) (a) Sun, L.; Zeng, W.; Xie, C.; Hu, L.; Dong, X.; Qin, F.; Wang, W.; Liu, T.; Jiang, X.; Jiang, Y. Adv. Mater. 2020, 32, 1907840. (b) Luo, Z.; Liu, T.; Xiao, Y.; Yang, T.; Chen, Z.; Zhang, G.; Zhong, C.; Ma, R.; Chen, Y.; Zou, Y. Nano Energy 2019, 66, 104146. (c) Gao, W.; Liu, 
Organic Materials

B. Liu et al.

THIEME

OPEN
ACCFSS

Original Article

T.; Sun, R.; Zhang, G.; Xiao, Y.; Ma, R.; Zhong, C.; Lu, X.; Min, J.; Yan, H. Adv. Sci. 2020, 7, 1902657.

(21) Mihailetchi, V. D.; Wildeman, J.; Blom, P. W. Phys. Rev. Lett. 2005, 94, 126602.
(22) Bartesaghi, D.; Pérez Idel, C.; Kniepert, J.; Roland, S.; Turbiez, M.; Neher, D.; Koster, L. Nat. Commun. 2015, 6, 7083.

(23) Tumbleston, J. R.; Collins, B. A.; Yang, L.; Stuart, A. C.; Gann, E.; Ma, W.; You, W.; Ade, H. Nat. Photonics 2014, 8, 385. 